\section{D) Check for updates}

Cite this: Food Funct., 2021, 12, 771

\title{
Effect of industrial processing and storage procedures on oxysterols in milk and milk products $\uparrow$
}

\author{
D. Risso, (iD $\star^{a} t^{a}$ V. Leoni, $t^{b}$ C. Fania, ${ }^{b}$ M. Arveda, ${ }^{a}$ L. Falchero, ${ }^{a}$ M. Barattero, ${ }^{c}$ A. Civra, ${ }^{d}$ \\ D. Lembo, ${ }^{d}$ G. Poli ${ }^{d}$ and R. Menta ${ }^{a}$
}

\begin{abstract}
Oxysterols are products of enzymatic and/or chemical cholesterol oxidation. While some of the former possess broad antiviral activities, the latter mostly originate from the deterioration of the nutritional value of foodstuff after exposure to heat, light, radiation and oxygen, raising questions about their potential health risks. We evaluated the presence of selected oxysterols in bovine colostrum and monitored the evolution of their cholesterol ratio throughout an entire industrial-scale milk production chain and after industrially employed storage procedures of milk powders. We report here for the first time the presence of high levels of the enzymatic oxysterol 27-hydroxycholesterol $(27 \mathrm{OHC})$ in concentrations of antiviral interest in bovine colostrum (87.04 $\mathrm{ng} \mathrm{mL}^{-1}$ ) that decreased during the first postpartum days (56.35 $\mathrm{ng}$ $\mathrm{mL}^{-1}$ ). Of note, this oxysterol is also observed in milk and milk products and is not negatively affected by industrial processing or storage. We further highlight an exponential increase of the non-enzymatic oxysterols $7 \beta$-hydroxycholesterol $(7 \beta \mathrm{OHC})$ and 7 -ketocholesterol $(7 \mathrm{KC})$ in both whole (WMPs) and skimmed milk powders (SMPs) during prolonged storage, confirming their role as reliable biomarkers of cholesterol oxidation over time: after 12 months, $7 \beta O H C$ reached in both SMPs and WMPs amounts that have been found to be potentially toxic in vitro $\left(265.46 \mathrm{ng} \mathrm{g}^{-1}\right.$ and $569.83 \mathrm{ng} \mathrm{g}^{-1}$, respectively). Interestingly, industrial processes appeared to affect the generation of $7 \beta \mathrm{OHC}$ and $7 \mathrm{KC}$ differently, depending on the presence of fat in the product: while their ratios increased significantly after skimming and processing of skimmed milk and milk products, this was not observed after processing whole milk and milk cream.
\end{abstract}

Received 17th September 2020, Accepted 9th December 2020

DOI: $10.1039 / \mathrm{dOfo} 02462 \mathrm{~g}$

rsc.li/food-function may trigger cholesterol oxidation. Nutritionists have focused on both enzymatic and non-enzymatic oxysterols because they mediate many pathophysiological functions including cellular toxicity and inhibition of DNA synthesis, but also regulate a variety of cell functions including innate and adaptative immunity and some possess broad antiviral activities. ${ }^{3-5}$

Over the last few years, growing evidence is clearly indicating how only oxysterols of enzymatic origin and in particular the side chain oxysterols 25-hydroxycholesterol and 27-cholesterol may have a pleiotropic physiological role. ${ }^{6,7}$ Non-enzymatic oxysterols, in particular 7-ketocholesterol (7KC) and $7 \beta$-hydroxycholesterol $(7 \beta \mathrm{OHC})$, have been defined as accurate markers of cholesterol auto-oxidation, as their concentration heavily increases during inflammation and other processes characterized by cell and tissue oxidative stress. ${ }^{8-10}$ In this relation, it is worth outlining that cholesterol oxidation products (COPs) often measured in foodstuffs belong to the not enzymatic oxysterol sub-family.

Total COPs in foods amount, on average, to $1 \%$ of the cholesterol content: however, this number may be as high as over $10 \%$, depending on the processing conditions (e.g. 
heating temperature, length of heating time, UV irradiation, UHT, desiccation), storage time, and type of packaging. ${ }^{11}$ Even a storage time as short as ten hours has been shown to affect the generation of COPs and the decrease of the antioxidant potential of the product. ${ }^{12}$ Fresh foods, because of their low oxygen content, have been reported to contain very low levels of cholesterol oxides. Very early analyses claimed their complete absence in fresh milk, attributing their generation only to oxygen exposure, $\mathrm{pH}$ decrease, and technological activities. $^{1,2}$ However, a few more recent studies, with the development of more sensible methods for cholesterol oxides determination, have disclosed their presence in raw milk, both of cow and human origin. ${ }^{6,13}$ While earlier studies reported that no or only limited amounts of oxysterols were formed during heating of milk under commercial pasteurization or UHT-treatments, a more recent study has shown that pasteurization and UHT treatments increase the amount of COPs significantly, up to $58 \%$ in bovine milk and $42 \%$ in caprine milk, when compared to raw milk. ${ }^{13-15}$ These discrepancies may be attributed, at least in part, to the lack of a generally accepted standardized method for determining COPs in different food matrices. The variability of indicators such as linearity range, detection limit, repeatability and recovery rate of the various analytical methods that have been developed for quantifying COPs in food surely increases entropy. Because of their presence at very low concentration and their overall unstable nature, COPs could be degraded easily or, at the contrary, artifacts may be formed during their extraction. ${ }^{2}$ In addition, it has been shown that non-negligible amounts of cholesterol are present in feedstuffs and can influence the lipid portion of the derived foods. Therefore, the presence and quantity of cholesterol-derived compounds in milk and derived products may also be affected by the sterol profile of the animal feed. ${ }^{16}$

The major oxysterol species found in animal products are $7 \alpha$-hydroxycholesterol $\quad(7 \alpha \mathrm{OHC}), \quad 7 \beta$-hydroxycholesterol

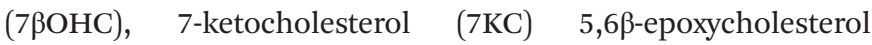
( $\beta$-epoxy), 5,6 $\alpha$-epoxycholesterol ( $\alpha$-epoxy), cholestan$3 \beta, 5 \alpha, 6 \beta$-triol (Triol), 25-hydroxycholesterol (25OHC). ${ }^{13,17,18}$ Some of these compounds have received particular attention due to their potential toxicity: in particular, $7 \beta \mathrm{OHC}$ and $7 \mathrm{kC}$ have been reported to be important indicators of the storage conditions of liquid milk, milk powders, butter and eggderived products, highlighting their role as biomarkers of cholesterol oxidation..$^{1,12,19} 25 \mathrm{OHC}$, the only side chain oxysterols measured so far in dairy products and at the same time the only side chain oxysterol also generated by auto-oxidation, has gained recent interest because of its broad-spectrum antiviral activity. ${ }^{20,21}$ In this regard, in spite of the emerging role of another oxysterol of strictly enzymatic production, i.e.27-hydroxycholesterol $(27 \mathrm{OHC})$ in the innate immunity and antiviral defenses, ${ }^{5,6,22-24}$ to date no data have been published on its presence, or absence, in commonly consumed food product. Of note, $27 \mathrm{OHC}$ is the quantitatively most represented oxysterol in human blood ${ }^{25,26}$ and shows a remarkably high concentration in the human colostrum. ${ }^{6}$ Moreover, of extreme importance is the very recent discovery that $27 \mathrm{OHC}$ inhibits in vitro SARS-CoV-2 and one of the common cold agents HCoV-OC43 and is markedly decreased in COVID-19. ${ }^{27}$

Because of both potential health risks and advantages of oxysterols, their formation and presence in foods have been the subject of many studies. In the scientific literature, however, most of the available information on food products derives from analyses performed on commercially available samples that have undergone unknown processing (temperature, length of processing, oxygen exposure), transportation, and packaging conditions. No comprehensive report on the generation and variation of oxysterol ratios following an industrial milk production chain step-by-step with stable, replicable, processing conditions is to date available.

For these reasons, we analyzed the content of cholesterol and selected oxysterols in colostrum, milk and milk products collected throughout the entire production chain and across key processing treatments (i.e. fresh raw milk, pasteurized, concentrated, skimmed, transformed in milk cream and anhydrous fat, spray-dried) and after prolonged storage of milk powders (i.e. fresh, 6 and 12 months old) of an Italian dairy supplier. The aim of the study was to further explore the role of both enzymatic (i.e. 27OHC) and non-enzymatic (i.e. 7ßOHC and $7 \mathrm{KC}$ ) oxysterols, although keeping a net distinction between the two sub-classes, as nutritional markers and quality tools to monitor cholesterol oxidation in milk and milk products, of use to the food and ingredient industry.

$7 \beta \mathrm{OHC}$ and $7 \mathrm{KC}$ were selected as the most trustable indices of cholesterol autoxidation not only because the most represented in both liquid and powdered milk and derivatives, ${ }^{12,13,17,18}$ but also because much less affected by the quite complex analytical determination procedures than other oxysterols such as $\beta$-epoxides. ${ }^{28}$ Moreover, a large body of literature specifically points to the potential broad cytotoxicity of $7 \beta \mathrm{OHC}$ and $7 \mathrm{KC}$, when present in excess amounts. ${ }^{10}$

$27 \mathrm{OHC}$ was chosen in light of its solely enzymatic production and because of its promising emerging nutritional properties, as discussed above. In addition, to our knowledge, its presence in foodstuff still remains to be examined. Other oxysterols such as $25 \mathrm{OHC}$ and $7 \alpha \mathrm{OHC}$ are in fact of both enzymatic and non-enzymatic origin, ${ }^{29-31}$ and have already been recorded, although at low levels, in milk and dairy products. $^{2,13,17}$

\section{Materials and methods}

\section{Milk and milk samples}

Different bovine milk and milk products were included in this study. Firstly, three samples of bovine colostrum were freshly collected from an Italian farm on days 1, 2, 3 postpartum. A series of 16 milk and milk products were then collected throughout an entire industrial-scale production of milk and anhydrous fat (Tetrapak, Sweden) from a customized manufacturing plant of the Italian dairy producer Inalpi SpA (Table 1): replicate analyses of aliquots of four different production batches were performed for each collected sample and the 
Table 1 Milk and milk products analyzed in the current study

\begin{tabular}{|c|c|c|c|}
\hline Milk and derivates $(N=4$ for each sample $)$ & $\begin{array}{l}\text { Dry matter, } \\
\text { total solids (\%) }\end{array}$ & $\begin{array}{l}\text { Milk solids, } \\
\text { non-fat (\%) }\end{array}$ & $\begin{array}{l}\text { Fat content } \\
(\%)\end{array}$ \\
\hline Fresh raw whole-milk, unprocessed & $12.0-13.5$ & $8.6-9.3$ & $3.4-4.2$ \\
\hline Skimmed milk, prepasteurized & $8.6-8.9$ & $8.6-8.9$ & $0.01-0.02$ \\
\hline Milk cream, prepasteurized & $43-45$ & 3.0 & $40-42$ \\
\hline Whole-milk, standardized, pasteurized at standard parameters $\left(72^{\circ} \mathrm{C}\right.$ for $\left.15 \mathrm{~s}\right)$ & $11.2-12.2$ & $8-8.6$ & $3.2-3.6$ \\
\hline Whole-milk, concentrated and treated at higher temperature $\left(85^{\circ} \mathrm{C}\right.$ for $\left.40 \mathrm{~s}\right)$ & $51-52$ & $36.7-38.4$ & $13.2-14.2$ \\
\hline Skimmed milk, pasteurized at standard parameters $\left(72^{\circ} \mathrm{C}\right.$ for $\left.15 \mathrm{~s}\right)$ & $8.5-9.6$ & $8.5-9.5$ & $0.07-0.10$ \\
\hline Skimmed milk, concentrated and treated at higher temperature $\left(85^{\circ} \mathrm{C}\right.$ for $\left.40 \mathrm{~s}\right)$ & $51-52$ & $50.6-51.6$ & $0.35-0.45$ \\
\hline Milk cream, pasteurized at standard parameters $\left(85-90^{\circ} \mathrm{C}\right.$ for $\left.15 \mathrm{~s}\right)$ & $43-45$ & 3.0 & $40-42$ \\
\hline Anhydrous Milk Fat & 99.8-99.9 & 0.1 & 99.8 \\
\hline Whole-milk powder (WMP), fresh & 97-98 & $71-72$ & $26-27$ \\
\hline WMP, shelf-life 6 months & 97-98 & $71-72$ & $26-27$ \\
\hline WMP, shelf-life 12 months & 97-98 & $71-72$ & $26-27$ \\
\hline Skimmed-milk powder (SMP), fresh & $96.5-97.5$ & $95.5-96.8$ & $\operatorname{Max} 1.5(0.7-1)$ \\
\hline SMP, shelf-life 6 months & $96.5-97.5$ & $95.5-96.8$ & $\operatorname{Max} 1.5(0.7-1)$ \\
\hline SMP, shelf-life 12 months & $96.5-97.5$ & $95.5-96.8$ & $\operatorname{Max} 1.5(0.7-1)$ \\
\hline
\end{tabular}

reported dry matter, milk solids and fat content values are based on 500 routine analyses. The collected samples belonged to the following steps of the production chain: fresh raw whole-milk, skimmed milk, raw milk cream, pasteurized standardized whole and skimmed milk, concentrated whole and skimmed milk treated at higher temperature, pasteurized milk cream, anhydrous milk fat, fresh spray-dried whole (WMP) and skimmed milk powder (SMP), stored WMP and SMP (6 and 12 months).

\section{Industrial sampling and processing}

Fresh raw milk and anhydrous milk fat were collected from different Italian farms $(\approx 400)$, mainly breeding Italian Friesian cows $(70 \%)$, Italian Red Pied (18\%), and other dairy breeds (12\%). After being stored at $4{ }^{\circ} \mathrm{C}$ for max 48 hours, milk was then first skimmed by centrifugation and, depending on the type of production (i.e. whole or skimmed), reconstituted and standardized with milk fat and lactose. Both skimmed and whole milk were then processed under different conditions, namely standard legal pasteurization (STD, $72{ }^{\circ} \mathrm{C}$ for $15 \mathrm{~s}$ ) and pre-heating treatment before concentration at $51-52 \%$ milk solids (HT, $85{ }^{\circ} \mathrm{C}$ for $40 \mathrm{~s}$ for whole milk, $85{ }^{\circ} \mathrm{C}$ for $190 \mathrm{~s}$ for skimmed). Fifteen milliliters samples were collected in disposable sterile Eppendorf tubes, immediately placed at $-50{ }^{\circ} \mathrm{C}$ and transported at $4{ }^{\circ} \mathrm{C}$, before being stored at $-80{ }^{\circ} \mathrm{C}$ until tested (within 48 hours after collection) in order to minimize every degeneration process. Skimmed milk (SMP) and whole milk powders (WMP) were produced after the highertemperature treatment by two subsequent vacuum evaporations, first using Mechanical Vapor Recompression (MVR), involving the use of a compressor, and then Thermal Vapor Recompression (TVR) performed by steam ejector to reach total milk solids of $48 \%$ and $51 \%$, respectively to reach a whey protein nitrogen index (WPNI) between 2.0 and 2.5 for SMP and 3.0 and 3.5 for WMP. Concentrated liquid milks were spray-dried using industrial conditions and equipment. Drying was performed in an industrial spray-drying tower and using high-pressure nozzle technology, operating with an inlet air temperature of $190-220^{\circ} \mathrm{C}$, depending on the production with an outlet temperature of $70-75{ }^{\circ} \mathrm{C}$ for WMP and $80-85{ }^{\circ} \mathrm{C}$ for SMP. The moisture content after this stage is around 3.8-4.0. The powders were further dried in a vibrating drying belt to get a final moisture of 2.0-3.0 for WMP and 2.5-3.5 for SMP. Five grams samples of SMPs and WMPs were collected right after drying belt stage in disposable sterile Eppendorf tubes immediately after production and stored in the dark at $4{ }^{\circ} \mathrm{C}$ until tested (within 48 hours after collection). In addition, SMP and WMP from different batches but produced under the same industrial conditions were collected after storage at $20 \pm$ $2{ }^{\circ} \mathrm{C}$ and $<65 \% \mathrm{RH}$ for 6 and 12 months in the dark under non-vacuum conditions. Centrifuged milk cream $40 \%$ was also used to produce anhydrous milk fat $(99.8 \%)$. Cream was pasteurized in a plate heat exchanger and further concentrated to obtain $78 \%$ fat. Thus, the concentrated cream was homogenized for phase inversion and fat globules disruption, following a further concentration to $99.5 \%$ fat and a final polishing step and a vacuum treatment to obtain anhydrous milk fat $(99.8 \%$ fat). Milk cream before and after pasteurization at standard parameters $\left(85-90{ }^{\circ} \mathrm{C}\right.$ for $\left.15 \mathrm{~s}\right)$ and anhydrous milk fat were also collected in disposable Eppendorf tubes, immediately placed at $-50{ }^{\circ} \mathrm{C}$, and transported at $4{ }^{\circ} \mathrm{C}$, before being stored at $-80^{\circ} \mathrm{C}$ until tested (within 48 hours after collection).

\section{Cholesterol and oxysterols determination}

To a screw-capped vial sealed with a Teflon septum, $1 \mathrm{ml}$ of milk or colostrum, $1 \mathrm{ml}$ of a $100 \mathrm{mg} \mathrm{mL}^{-1}$ distilled water suspended powered milk or $250 \mathrm{~mL}$ of cream or anhydrous butter were added together with $50 \mu \mathrm{g}$ of epicoprostanol (Sigma) 50 $\mathrm{ng}$ of $7 \beta$-hydroxycholesterol-25, 26, 26, 26, 27, 27, 27-d7 (d7$7 \beta \mathrm{OHC}$, Avanti Polar Lipids Inc. USA, SKU 700044P), $50 \mathrm{ng}$ of 7-ketocholesterol-25, 26, 26, 26, 27, 27, 27-d7 (d7-7KC, Avanti Polar Lipids Inc. USA, SKU: 700046P), $50 \mathrm{ng}$ of 27 -hydroxycholesterol -25, 26, 26, 26, 27, 27-d6 (d6-27OHC, Avanti Polar Lipids Inc. USA, SKU: 700059P) as internal standards, $50 \mu \mathrm{l}$ of butylatedhydroxytoluene (BHT, $5 \mathrm{~g} \mathrm{~L}^{-1}$ ) and $50 \mu \mathrm{l}$ of K3-EDTA $\left(10 \mathrm{~g} \mathrm{~L}^{-1}\right)$ to prevent auto-oxidation. Each vial was flushed with 
argon for $10 \mathrm{~min}$ to remove air. Alkaline hydrolysis was allowed to proceed at $4{ }^{\circ} \mathrm{C}$ overnight with magnetic stirring in the presence of ethanolic $2 \mathrm{M}$ potassium hydroxide solution. After hydrolysis, the sterols were extracted twice with $5 \mathrm{ml}$ of cyclohexane. $3 \mathrm{ml}$ of the cyclohexane extract were used for cholesterol analysis. The oxysterols were separated from cholesterol and sterols by elution of the remaining $7 \mathrm{ml}$ on SPE cartridge (SI $100 \mathrm{mg}$ columns, Isolute) with isopropanol : hexane $30: 70 \mathrm{v} / \mathrm{v}$. The organic solvents were evaporated under a gentle stream of argon and converted into trimethylsilyl ethers with $100 \mu \mathrm{L}$ of BSTFA ( $60{ }^{\circ} \mathrm{C}$ for $60 \mathrm{~min}$ ). Analysis was performed by gas chromatography - isotope dilution mass spectrometry (GC-MS) with a B-XLB column $(30 \mathrm{~m} \times 0.25 \mathrm{~mm}$ i.d. $\times$ $0.25 \mu \mathrm{m}$ film thick-ness, J\&W Scientific Alltech, Folsom, CA, USA.) in a HP 6890 Network GC system (Agilent Technologies, USA) connected with a direct capillary inlet system to a quadruple mass selective detector HP5975B inert MSD (Agilent Technologies, USA). GC system was equipped with a HP 7687 series autosamplers and HP 7683 series injectors (Agilent Technologies, USA). The oven temperature program was as follows: initial temperature of $180{ }^{\circ} \mathrm{C}$ was held for $1 \mathrm{~min}$, followed by a linear ramp of $20^{\circ} \mathrm{C} \min ^{-1}$ to $270{ }^{\circ} \mathrm{C}$, and then a linear ramp of $5{ }^{\circ} \mathrm{C} \mathrm{min}^{-1}$ to $290{ }^{\circ} \mathrm{C}$, which was held for $11 \mathrm{~min}$. Helium was used as carrier gas at a flow rate of $1 \mathrm{ml}$ $\min ^{-1}$ and $1 \mu \mathrm{L}$ of sample was injected in splitless mode. Injection was carried at $250{ }^{\circ} \mathrm{C}$ with a flow rate of $20 \mathrm{ml} \mathrm{min}{ }^{-1}$. Transfer line temperature was $290{ }^{\circ} \mathrm{C}$. Filament temperature was set at $150{ }^{\circ} \mathrm{C}$ and quadrupole temperature at $220{ }^{\circ} \mathrm{C}$ according with the manufacturer indication. Mass spectrometric data were acquired in selected ion monitoring mode (OTMSi-ethers) at $m / z=463\left(\mathbf{M}^{+}\right.$-90) for $7 \beta$-hydroxycholesterol$\mathrm{d} 7, \mathrm{~m} / z=456\left(\mathbf{M}^{+}-90\right)$ for $7 \beta$-hydroxycholesterol (Sigma-Aldrich Inc. USA, SKU: H6891), $m / z=479\left(\mathbf{M}^{+}-90\right)$ for 7-ketocholesterol$\mathrm{d} 7, \mathrm{~m} / z=472\left(\mathbf{M}^{+}-90\right)$ for 7-ketocholesterol (Sigma-Aldrich Inc. USA, SKU: C2394), $m / z=462\left(\mathbf{M}^{+}-90\right)$ for 27-hydroxycholesterold6 and $m / z=456\left(\mathbf{M}^{+}-90\right)$ for 27-hydroxycholesterol (Avanti Polar Lipids Inc. USA, SKU: 700021P). Peak integration was performed manually, and oxysterols were quantified from selected-ion monitoring analysis against internal standards (available in the ESI, as Table S1 $\dagger$ ) using standard curves for the listed sterols. ${ }^{32-35}$

Replicated analysis of $1 \mathrm{~mL}$ of whole-milk, standardized, pasteurized at standard parameters $(n=12)$ resulted in an interassay $\mathrm{CV}$ as $3.87 \%$ for $7 \beta \mathrm{OHC}, 3.97 \%$ for $7 \mathrm{KC}$ and $3.13 \%$ for $27 \mathrm{OHC}$, respectively. Whole milk pasteurized at standard temperature was added with $25 \mathrm{ng}$ of $7 \beta \mathrm{OHC}, 7 \mathrm{KC}$ and $27 \mathrm{OHC}$, and analyzed as previously described ( $n=3$ independent experiments). Mean recovery (measured/expected \%) $102.7 \%$ for $7 \beta \mathrm{OHC}, 98.3 \%$ for $7 \mathrm{KC}$ and $101 \%$ for $27 \mathrm{OHC}$, respectively.

\section{Statistical analysis}

Continuous variables were inspected and tested to determine whether distributions were normal by Kolmogorov-Smirnov normality test, expressed as mean \pm SD and compared using ANOVA with the Scheffé post-test for parametric data, with
Holm-Sidak method for All Pirewise Multiple Comparison. Comparison between two groups was performed with two tailed Student's $t$-test, and values for statistical significance were set at $p<0.05$. All analyses were performed with Sigmastat 3.5 (SigmaAldrich, St Louis, MO, USA). Because of all the different intermediate steps of which an industrialscale milk production line is composed, most of the analyzed different milk and milk finished and semi-finished products varied in terms of fat percentage, cholesterol and dry matter content (Table 1). Being oxysterols products of the chemical and/or enzymatic oxidation of cholesterol, we expressed our results as ratios of oxysterols/cholesterol $\left(n g \mu \mathrm{g}^{-1}\right)$, for a more accurate assessment of the effects of different processing and storage procedures.

\section{Results and discussion}

\section{Oxysterols in bovine colostrum}

The first analyses carried out were those on the oxysterols content of bovine colostrum, primed by a recent report illustrating the presence of these compounds in the human colostrum, intermediate and mature milk. ${ }^{6}$ As reported in Fig. 1, the bovine colostrum, as in the case of the human one, showed a marked peak concentration of $27 \mathrm{OHC}$ since the first day after delivery $\left(87.04 \pm 7.04 \mathrm{ng} \mathrm{mL}^{-1}\right)$, rapidly lowering in the following few days and decreasing by day 3 postpartum to $56.35 \pm 13.50 \mathrm{ng} \mathrm{mL}^{-1}(P=0.038$; Fig. 1$)$. These concentrations have been shown on in vitro cell lines to efficiently inhibit the replication of different viruses, including human rotavirus, the agent of gastroenteritis in infants. ${ }^{6,36} 7 \beta \mathrm{OHC}$ and $7 \mathrm{KC}$, although at significantly lower quantities than 27OHC $(P<$ 0.001; Fig. 1), were also present in bovine colostrum, without showing a reduction between postpartum days $(P=0.247$ and $P=0.777$, respectively; Fig. 1), as also reported for human colostrum. ${ }^{6}$ Of note, cholesterol in bovine colostrum showed a progressive reduction from $609.33 \pm 111.2 \mu \mathrm{g} \mathrm{mL} \mathrm{m}^{-1}$ of day one to $287.45 \pm 61.87 \mu \mathrm{g} \mathrm{mL}^{-1}$ of day three after delivery $(P=$ 0.015), as also observed in human colostrum. ${ }^{6}$

\section{Oxysterols in milk and milk products: effects of processing}

Bovine whole milk. Bovine fresh raw whole milk contained $102.93 \pm 9.62 \mu \mathrm{g} \mathrm{ml}{ }^{-1}$ cholesterol, an amount compatible with published data. ${ }^{12,37}$ Although at low concentrations, 7 $\beta \mathrm{OHC}$ and $7 \mathrm{KC}$ were present in fresh raw milk (12.46 \pm 0.78 and $13.68 \pm 0.92 \mathrm{ng} \mathrm{mL} \mathrm{m}^{-1}$, respectively), while earlier studies reported a complete absence of oxysterols in fresh milk products. ${ }^{1,2,13}$ An example of a total ion count (TIC) chromatogram of a raw milk sample, analyzed as described in the materials and methods, is reported in the ESI as Fig. S1. $\dagger$ As in the colostrum, although at notably lower concentrations, $27 \mathrm{OHC}$ was the most represented oxysterol found in fresh milk in concentrations of $33.62 \pm 2.43 \mathrm{ng} \mathrm{mL}^{-1}(P<0.001)$. Notably, a similar difference was reported between human colostrum and mature milk: considering the in vitro demonstrated antiviral potency of this oxysterol, it was hypothesized that this 


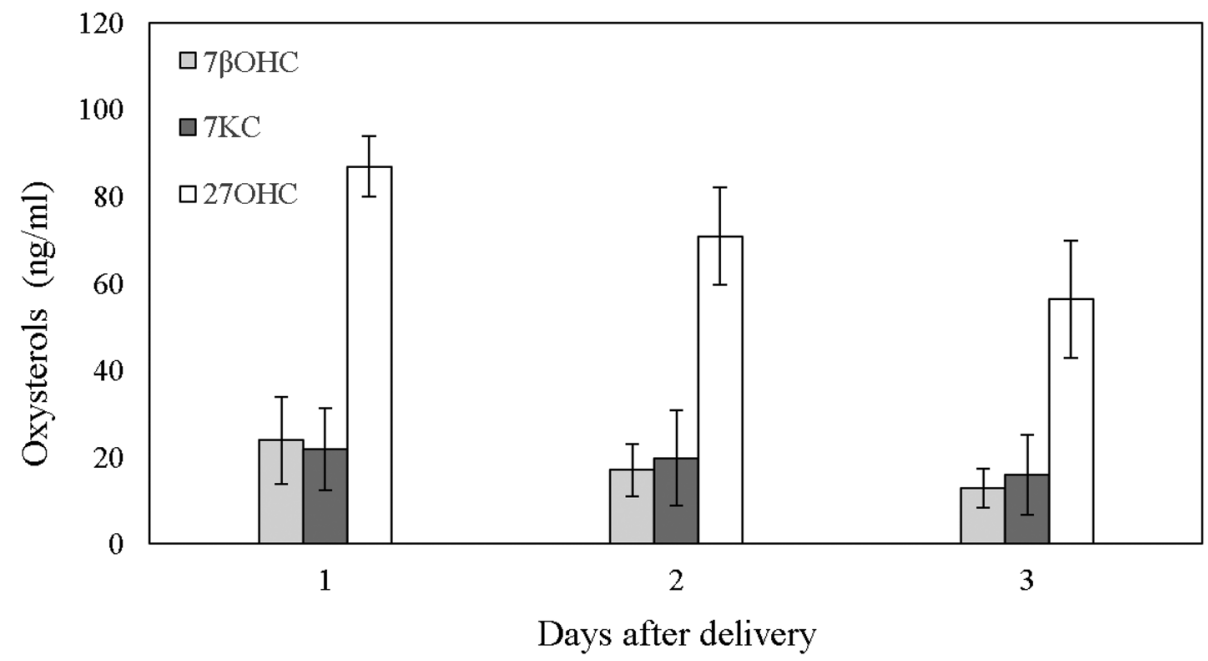

Fig. 1 Oxysterols in bovine colostrum at days 1,2 and 3 after delivery. Values are means \pm SD of three different samples. $7 \beta O H C$ : 7 $\beta$-hydroxycholesterol; 7KC: 7-ketocholesterol; 27OHC: 27-hydroxycholesterol.

different distribution may be attributed to a passive transfer of innate immunity factors exerting a protective role during the first days of the newborn. ${ }^{6}$ No changes in the $7 \beta \mathrm{OHC} /$ cholesterol ratio (R7ßOHC, $P>0.05$ ) and in $27 \mathrm{OHC} /$ cholesterol ratio (R27OHC, $P>0.05$ ) between raw and standardly pasteurized milk were observed (Fig. 2 and Table 2), while the ratio of 7KC (R7KC) showed an increase ( $P=0.029$; Fig. 2 and Table 2$)$, in line with previous studies illustrating that only limited amounts of oxysterols were formed during heating of wholemilk at $85{ }^{\circ} \mathrm{C}$ or below. ${ }^{2,14}$ After a second treatment at higher temperature, followed by concentration, $\mathrm{R} 7 \beta \mathrm{OHC}$ was reduced by $46 \%(P=0.029)$, R7KC by a $58 \%(P<0.001)$ and $\mathrm{R} 27 \mathrm{OHC}$ by a $18 \%,(P=0.029)$, respectively (Fig. 2 and Table 2$)$. Such behavior may be explained by the ability of free water to signifi- cantly influence lipid oxidation processes and/or by the effects that milk solids concentration exerts on milk nutrient denaturation and modifications, as previously reported..$^{38-40}$

Bovine skimmed milk. Bovine raw skimmed milk showed a residual cholesterol level of $20.85 \pm 0.41 \mu \mathrm{g} \mathrm{ml}{ }^{-1}$. As a result of the skimming process, the R7ßOHC $(P=0.029)$, R7KC $(P=$ $0.029)$ and $270 H C$ increased significantly $(P=0.004$; Fig. 2 and Table 2), in line with published data reporting similar observations. ${ }^{17,38}$ Following standard pasteurization of skimmed milk, R7ßOHC decreased by $28 \%(P=0.003)$ and R7KC by $44 \%(P<0.001)$, respectively (Fig. 2 and Table 2$)$. However, a second treatment of skimmed milk at higher temperatures, followed by concentration, appeared to significantly increase the ratio of all oxysterols $(P<0.001$ compared to raw

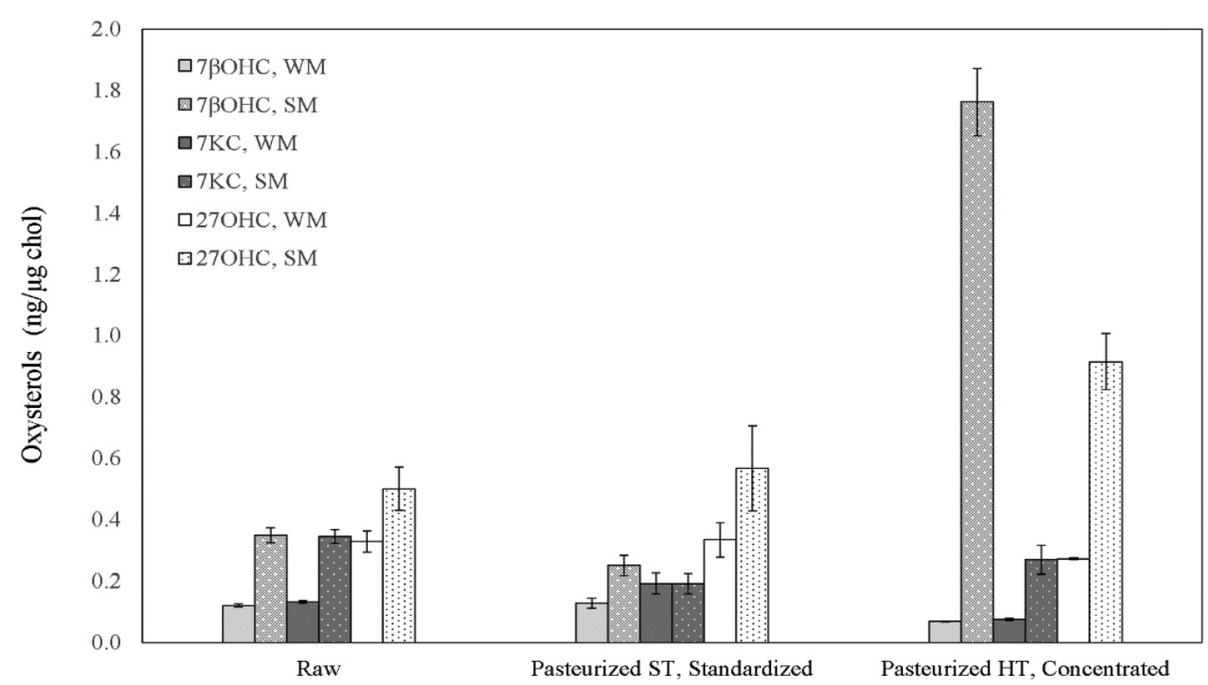

Fig. 2 Oxysterols in raw and thermally treated bovine liquid whole (WM) and skimmed milk (SM). Values are expressed as ng oxysterol per $\mu \mathrm{g}$ chole-

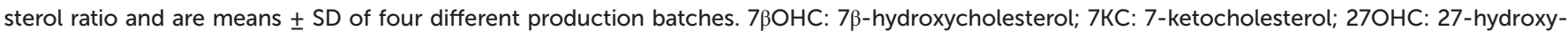
cholesterol. ST: standard temperature; HT: higher temperature. 


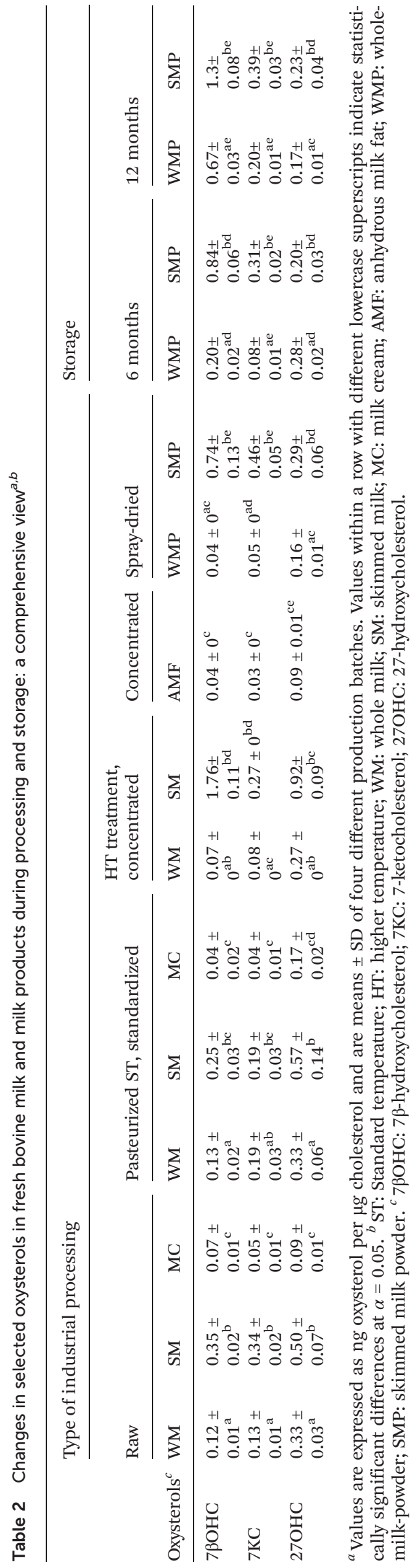

skimmed milk, $P<0.05$ compared to pasteurized skimmed milk; Fig. 2 and Table 2). Previous studies reported differential oxysterol formation or deterioration patterns in semi-skimmed and skimmed milks that underwent different heating and processing stress, when compared to whole-milks, suggesting that the higher level of free water in skimmed milk may facilitate oxysterols formation under more pronounced processing conditions, pointing to a potential protecting role of fat and antioxidant compounds present in milks with higher fat contents. ${ }^{17,38,41}$ Although we cannot exclude the occurrence of artifacts, considering the narrow standard deviation and the replicable results, both in terms of cholesterol and oxysterol contents over four different production batches, we deem this possibility unlikely.

Bovine milk cream and fat. Unpasteurized milk cream contained an average cholesterol amount of 744.6 $\pm 50.4 \mu \mathrm{g} \mathrm{g}^{-1}$, in line with values reported for milk creams of similar composition. ${ }^{37}$ The standard pasteurization process produced a reduction in terms of R7ßBHC $(P=0.002)$ but not for R7KC $(P$ $>0.05$; Fig. 3 and Table 2). Interestingly, the content of $27 \mathrm{OHC}$ after pasteurization was roughly doubled compared to the unpasteurized milk ( $P<0.001$; Fig. 3 and Table 2). Similarly, after centrifugations and processing to produce anhydrous milk fat, R7 $\beta \mathrm{OHC}$ was reduced $(P<0.001)$ while R7KC did not change $(P>0.05$; Fig. 3 and Table 2). R27OHC decreased significantly, returning to similar ratios observed in raw milk cream $(P<0.001$; Fig. 3 and Table 2$)$. To our knowledge, no comprehensive study has investigated the effect of common industrial processing on the stability of oxysterols in milk cream and anhydrous milk fat before. However, a few studies have also reported a differential non-linear increase or decrease of individual enzymatic and non-enzymatic oxysterols in butter subjected to different heating times and intensity, suggesting a potential matrix-effect in products with high fat content, also affected by the amount of free water and content of salt in the product. ${ }^{2,17,42}$ In addition, even a storage time as short as 10 hours at $3{ }^{\circ} \mathrm{C}$ has been shown to change the direction of cholesterol oxidation of cream-derived products, increasing some oxysterols while decreasing others. ${ }^{12}$

\section{Oxysterols in WMPs and SMPs: effects of storage}

Fresh WMP contained an average $898.41 \pm 32.04 \mu \mathrm{g} \mathrm{g}^{-1}$ cholesterol. Although the cholesterol content after spray-drying increased by roughly 14 times compared to pasteurized wholemilk, the increase in the three measured oxysterols did not follow the same increase ratio, exhibiting, on average, only about a 5-fold increase and reaching absolute 7ßOHC, 7KC and $27 \mathrm{OHC}$ amounts of $37.63 \pm 3.78,43.71 \pm 6.22$ and $141.21 \pm$ $5.78 \mathrm{ng} \mathrm{mg}^{-1}$, respectively $(P<0.05)$. These concentrations are comparable to the ones detected within the physiological range in human peripheral blood of normocholesterolemic adult subjects. ${ }^{43}$ In SMP, the residual cholesterol level was quantified as an average of $161.69 \pm 15.78 \mu \mathrm{g} \mathrm{g}^{-1}$. Differently from WMP, although the cholesterol content after spray-drying of pasteurized skimmed milk increased by approximately 7 times, the three measured oxysterols were found to increase by 


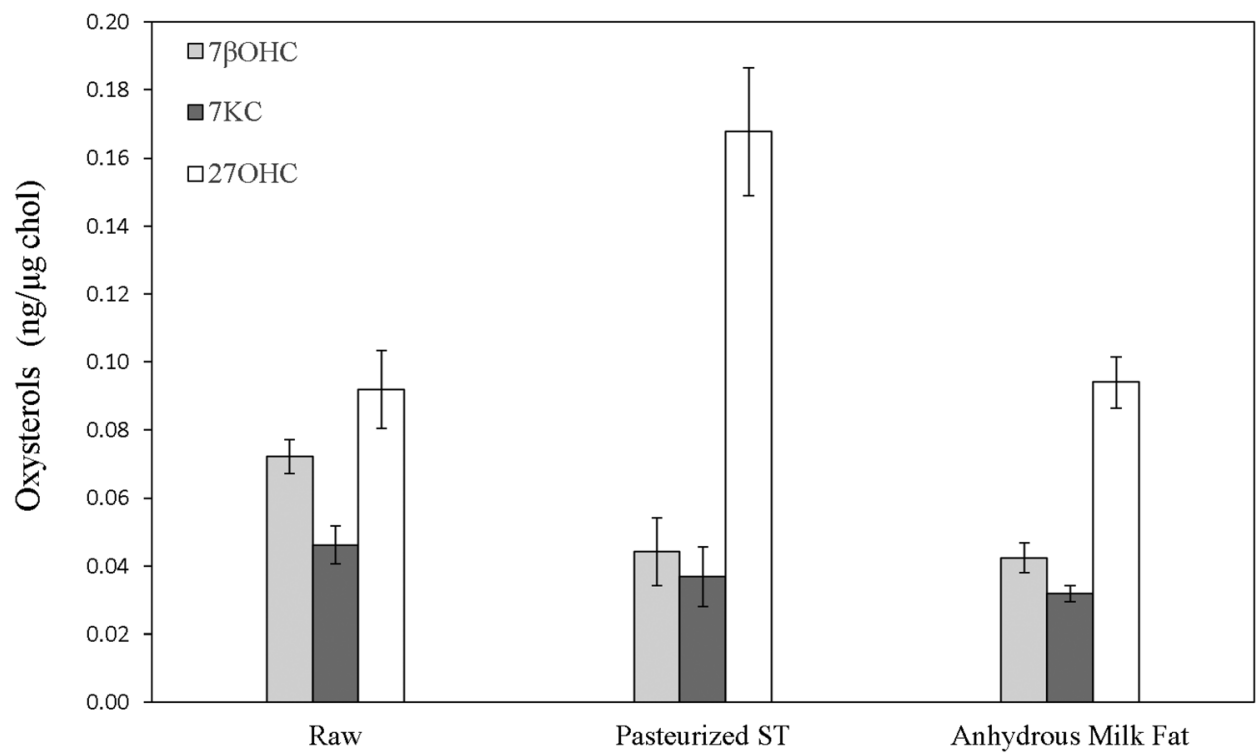

Fig. 3 Oxysterols in raw and thermally treated bovine milk cream and anhydrous fat. Values are expressed as ng oxysterol per $\mu \mathrm{g}$ cholesterol and

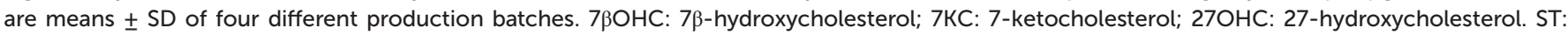
standard temperature.

roughly 14 times, reaching absolute values of $117.61 \pm 13.59$, $74.53 \pm 1.83$ and $46.34 \pm 9.56 \mathrm{ng} \mathrm{mg}^{-1}(P<0.05$; Table 2$)$. As in liquid milk, SMPs contained noticeably higher R7 $\beta \mathrm{OHC}(P=$ $0.029)$, R7KC $(P=0.029)$ and R27OHC $(P=0.006)$ than WMPs $(P<0.05$; Fig. 4 , Table 2$)$, a result that finds confirmation in previous studies. $^{2,41,44}$

$7 \beta \mathrm{OHC}$ and $7 \mathrm{KC}$ were found to be particularly effective predictors of storage time in WMP: after 6 months, the increase of their ratio was $5(P<0.001)$ and 1.6-fold $(P<0.001)$, respectively (Fig. 4, Table 2), in agreement with previous findings defining them as effective and reliable markers of autoxidation across storage time in powdered foodstuff. ${ }^{19,41,44}$ After 12 months, their amounts further increased by $16.8(P<0.001)$ and 4 -fold $(P<0.001)$, respectively (Fig. 4, Table 2). A similar trend was identified in SMPs, with $\mathrm{R} 7 \beta \mathrm{OHC}$ increasing over time $(P<0.001$; Fig. 4, Table 2$)$, with a difference regarding R7KC, which did not show a clear trend over time $(P>0.05$; Fig. 4, Table 2). Of notable importance is the fact that the absolute content of $7 \beta \mathrm{OHC}$ at 12 months reached $265.46 \pm$ $22.42 \mathrm{ng} \mathrm{g}^{-1}$ and $569.83 \pm 42.28 \mathrm{ng} \mathrm{g}^{-1}$ in SMPs and WMPs, respectively: amounts that have been found to be potentially toxic in several in vitro and in vivo experimental models. ${ }^{10,36,45}$

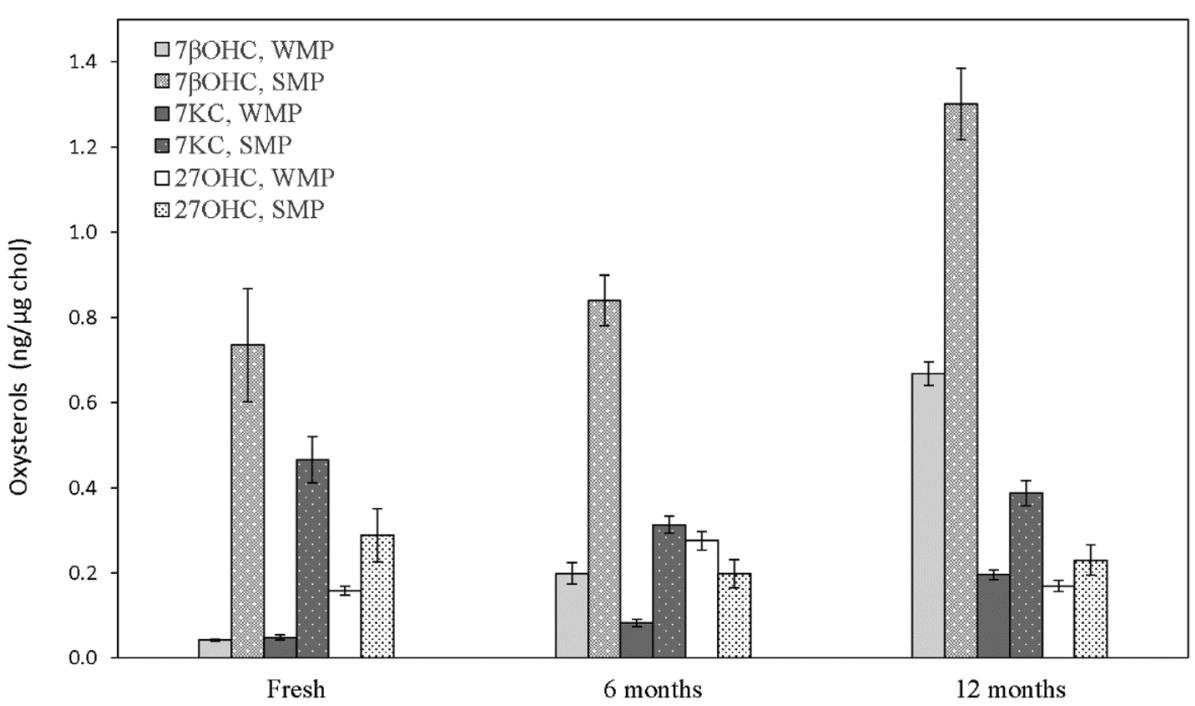

Fig. 4 Oxysterols in whole-milk (WMP) and skimmed milk powders (SMPs) stored for different amounts of time. Values are expressed as ng oxysterol per $\mu \mathrm{g}$ cholesterol and are means \pm SD of four different production batches. $7 \beta \mathrm{OHC}$ : 7 $\beta$-hydroxycholesterol; 7KC: 7-ketocholesterol; $27 \mathrm{OHC}$ : 27-hydroxycholesterol. 
Interestingly, R27OHC showed an increase across storage time in WMPs, with a peak at 6 months $(P<0.001)$. In SMPs we did not observe a reduction $\mathrm{R} 27 \mathrm{OHC}$ over time $(P>0.05$; Fig. 4 , Table 2). Although this is the first study to test for the presence of $27 \mathrm{OHC}$ in bovine milk products, other enzymatic or semienzymatic oxysterols have been reported to show a non-linear increase with storage time, suggesting that prolonged exposure to oxygen may not represent a strong driver of generation of these enzymatic compounds. ${ }^{2,40,44}$

\section{Conclusions}

Although earlier studies reported a complete absence of oxysterols in unprocessed products, showing their occurrence only after exposure to oxygen, $\mathrm{pH}$ decrease, and technological activities, our study highlights their presence in fresh milk and milk products, in line with more recent evidence. Remarkably, we found the oxysterol of enzymatic origin $27 \mathrm{OHC}$ in concentrations provided with antiviral potential in bovine colostrum and in lower but still nutritionally relevant amounts in mature milk, which were not affected by industrial processing. Furthermore, we stressed the role of the non-enzymatic $7 \beta \mathrm{OHC}$ and $7 \mathrm{KC}$ as a duo of reliable biomarkers of cholesterol oxidation, thus pointing to quality deterioration indicators of prolonged storage of milk powders under non-vacuum conditions.

Overall, we highlighted how the measurement of a selected subset of enzymatic (i.e. 27OHC) and non-enzymatic (i.e. $7 \beta \mathrm{OHC}$ and $7 \mathrm{KC}$ ) oxysterols during and after a milk production chain could represent a useful tool to monitor and increase the commercial and nutritional value of milk and milk products under certain processing conditions and storage procedures. For a more comprehensive approach, we acknowledge the need for future studies to also address the determination and comparative evaluation of additional oxysterols, such as $7 \alpha \mathrm{OHC}$, epoxides and triol, to explore their possible inclusion in such tool.

\section{Author contributions}

Conceptualization, D. R., V. L., G. P., R. M.; data curation, D. R., V. L., G. P., C. F., M. A., L. F., A. C., M. B., D. L.; formal analysis, D. R., V. L., G. P., C. F.; methodology, D. R., V. L., G. P.; project administration, D. R., G. P., R. M.; resources, M. A., L. F., M. B., D. L., A. C., G. P., R. M., supervision, G. P., R. M.; validation D. R., G. P., R. M.; visualization, D. R., A. C., G. P.; writing-original draft, D. R., V. L., G. P.; writing-review \& editing, D. R., V. L., G. P., R. M., M. A., C. F. All authors have read and agreed to the published version of the manuscript.

\section{Conflicts of interest}

D. Risso, M. Arveda, L. Falchero and R. Menta are full-time employees of Soremartec Italia Srl, Alba (CN, Italy). M. Barattero is an employee of Inalpi SpA Moretta (CN), Italy.

\section{Acknowledgements}

The research was carried out thanks to the financial support of Soremartec Italia Srl, Alba (CN, Italy). The authors would like to thank Azienda Agricola Abbà Pietro \& Figli in Favria (TO) for kindly providing the colostrum samples.

\section{References}

1 G. P. Savage, P. C. Dutta and M. T. Rodriguez-Estrada, Cholesterol oxides: their occurrence and methods to prevent their generation in foods, Asia Pac. J. Clin. Nutr., 2002, 11, 72-78.

2 R. Sieber, Oxidised cholesterol in milk and dairy products, Int. Dairy J., 2005, 15, 191-206.

3 G. Poli, F. Biasi and G. Leonarduzzi, Oxysterols in the pathogenesis of major chronic diseases, Redox Biol., 2013, 1, 125-130.

4 B. Vurusaner, G. Leonarduzzi, P. Gamba, G. Poli and H. Basaga, Oxysterols and mechanisms of survival signaling, Mol. Aspects Med., 2016, 49, 8-22.

5 D. Lembo, V. Cagno, A. Civra and G. Poli, Oxysterols: an emerging class of broad spectrum antiviral effectors, Mol. Aspects Med., 2016, 49, 23-30.

6 A. Civra, V. Leoni, C. Caccia, S. Sottemano, P. Tonetto, A. Coscia, C. Peila, G. E. Moro, P. Gaglioti, E. Bertino, G. Poli and D. Lembo, Antiviral oxysterols are present in human milk at diverse stages of lactation, J. Steroid Biochem. Mol. Biol., 2019, 193, 105424.

7 A. Civra, M. Colzani, V. Cagno, R. Francese, V. Leoni, G. Aldini, D. Lembo and G. Poli, Modulation of cell proteome by 25-hydroxycholesterol and 27-hydroxycholesterol: A link between cholesterol metabolism and antiviral defense, Free Radicals Biol. Med., 2020, 149, 30-36.

8 C. Zerbinati and L. Iuliano, Cholesterol and related sterols autoxidation, Free Radicals Biol. Med., 2017, 111, 151-155.

9 B. Sottero, D. Rossin, E. Staurenghi, P. Gamba, G. Poli; and G. Testa, Omics analysis of oxysterols to better understand their pathophysiological role, Free Radicals Biol. Med., 2019, 144, 55-71.

10 A. Vejux, D. Abed-Vieillard, K. Hajji, A. Zarrouk, J. J. Mackrill, S. Ghosh, T. Nury, A. Yammine, M. Zaibi, W. Mihoubi, H. Bouchab, B. Nasser, Y. Grosjean and G. Lizard, 7-Ketocholesterol and 7 $\beta$-hydroxycholesterol: In vitro and animal models used to characterize their activities and to identify molecules preventing their toxicity, Biochem. Pharmacol., 2020, 173, 113648.

11 S. J. Hur, G. N. Park and S. T. Joo, Formation of cholesterol oxidation products (COPs) in animal products, Food Control, 2007, 18, 939-947.

12 D. Cais-Sokolińska and M. Rudzińska, Short communication: Cholesterol oxidation products in traditional buttermilk, J. Dairy Sci., 2018, 101, 3829-3834.

13 J. M. Pikul, J. Rudzinska, A. Teichert, R. Lasik, R. Danków and R. Przybylski, Cholesterol oxidation during storage of 
UHT-treated bovine and caprine milk, Int. Dairy J., 2013, 30, 29-32.

14 M. Z. Cleveland and N. D. Harris, Oxidation of cholesterol in commercially processed cow's milk., J. Food Prot., 1987, 50, 867-871.

15 B. D. Sander, P. B. Addis, S. W. Park and D. E. Smith, Quantification of cholesterol oxidation products in a variety of foods, J. Food Prot., 1989, 52, 109-114.

16 G. Simonetti, P. Di Filippo, D. Pomata, C. Riccardi, F. Buiarelli, E. Sonego and F. Castellani, Characterization of seven sterols in five different types of cattle feedstuffs, Food Chem., 2021, 340, 127926.

17 M. Calderón-Santiago, M. A. Peralbo-Molina, F. PriegoCapote and M. D. Luque de Castro, Cholesterol oxidation products in milk: Processing formation and determination, Eur. J. Lipid Sci. Technol., 2012, 114, 687-694.

18 A. Gorassini, G. Verardo, S. C. Fregolent and R. Bortolomeazzi, Rapid determination of cholesterol oxidation products in milk powder-based products by reversed phase SPE and HPLC-APCI-MS/MS, Food Chem., 2017, 230, 604-610.

19 M. F. Caboni, E. Boselli, M. C. Messia, V. Velazco, A. Fratianni, G. Panfili and E. Marconi, Effect of processing and storage on the chemical quality markers of spray-dried whole egg, Food Chem., 2005, 92, 293-303.

20 S. Y. Liu, R. Aliyari, K. Chikere, G. Li, M. D. Marsden, J. K. Smith, O. Pernet, H. Guo, R. Nusbaum, J. A. Zack, A. N. Freiberg, L. Su, B. Lee and G. Cheng, Interferon-inducible cholesterol-25-hydroxylase broadly inhibits viral entry by production of 25-hydroxycholesterol, Immunity, 2013, 38, 92-105.

21 M. Blanc, W. Y. Hsieh, K. A. Robertson, K. A. Kropp, T. Forster, G. Shui, P. Lacaze, S. Watterson, S. J. Griffiths, N. J. Spann, A. Meljon, S. Talbot, K. Krishnan, D. F. Covey, M. R. Wenk, M. Craigon, Z. Ruzsics, J. Haas, A. Angulo, W. J. Griffiths, C. K. Glass, Y. Wang and P. Ghazal, The transcription factor STAT-1 couples macrophage synthesis of 25-hydroxycholesterol to the interferon antiviral response, Immunity, 2013, 38, 106-118.

22 Y. Son, S. M. Kim, S. A. Lee, S. K. Eo and K. Kim, Oxysterols induce transition of monocytic cells to phenotypically mature dendritic cell-like cells, Biochem. Biophys. Res. Commun., 2013, 438, 161-168.

23 S. Gargiulo, P. Gamba, G. Testa, D. Rossin, F. Biasi, G. Poli and G. Leonarduzzi, Relation between TLR4/NF-кB signaling pathway activation by 27-hydroxycholesterol and 4-hydroxynonenal, and atherosclerotic plaque instability, Aging Cell, 2015, 14, 569-581.

24 T. Willinger, Oxysterols in intestinal immunity and inflammation, J. Intern. Med., 2019, 285, 367-380.

25 I. Björkhem, V. Leoni and S. Meaney, Genetic connections between neurological disorders and cholesterol metabolism, J. Lipid Res., 2010, 51, 2489-2503.

26 V. Leoni and C. Caccia, Oxysterols as biomarkers in neurodegenerative diseases, Chem. Phys. Lipids, 2011, 164, 515-524.
27 A. Marcello, A. Civra, R. Milan Bonotto, L. Nascimento Alves, S. Rajasekharan, C. Giacobone, C. Caccia, R. Cavalli, M. Adami, P. Brambilla, D. Lembo, G. Poli and V. Leoni, The cholesterol metabolite 27-hydroxycholesterol inhibits SARS-CoV-2 and is markedly decreased in COVID-19 patients, Redox Biol., 2020, 36, 101682.

28 S. Dzeletovic, O. Breuer, E. Lund and U. Diczfalusy, Determination of cholesterol oxidation products in human plasma by isotope dilution-mass spectrometry, Anal. Biochem., 1995, 225(1), 73-80.

29 L. Iuliano, Pathways of cholesterol oxidation via non-enzymatic mechanisms, Chem. Phys. Lipids, 2011, 164, 457468.

30 O. Breuer and I. Björkhem, Simultaneous quantification of several cholesterol autoxidation and monohydroxylation products by isotope-dilution mass spectrometry, Steroids, 1990, 55(4), 185-192.

31 C. Helmschrodt, S. Becker, J. Schröter, M. Hecht, G. Aust, J. Thiery and U. Ceglarek, Fast LC-MS/MS analysis of free oxysterols derived from reactive oxygen species in human plasma and carotid plaque, Clin. Chim. Acta, 2013, 425, 38.

32 J. Acimovic, A. Lövgren-Sandblom, K. Monostory, D. Rozman, M. Golicnik, D. Lutjohann and I. Björkhem, Combined gas chromatographic/mass spectrometric analysis of cholesterol precursors and plant sterols in cultured cells, J. Chromatogr. B: Anal. Technol. Biomed. Life Sci., 2009, 877(22), 2081-2086.

33 D. Lütjohann, I. Björkhem, S. Friedrichs, A. Kerksiek, A. Lövgren-Sandblom, W. J. Geilenkeuser, R. Ahrends, I. Andrade, D. Ansorena, I. Astiasarán, L. Baila-Rueda, B. Barriuso, S. Becker, L. Bretillon, R. W. Browne, C. Caccia, U. Ceglarek, A. Cenarro, P. J. Crick, G. Fauler, G. Garcia-Llatas, R. Gray, W. J. Griffiths, H. Gylling, S. Harding, C. Helmschrodt, L. Iuliano, H. G. Janssen, P. Jones, L. Kaipiainen, F. Kannenberg, M. J. Lagarda, V. Leoni, A. M. Lottenberg, D. S. MacKay, S. Matysik, J. McDonald, M. Menendez-Carreño, S. B. Myrie, V. Sutti Nunes, R. E. Ostlund, E. Polisecki, F. Ramos, T. C. Rideout, E. J. Schaefer, G. Schmitz, Y. Wang, C. Zerbinati, U. Diczfalusy and H. F. Schött, First international descriptive and interventional survey for cholesterol andnon-cholesterol sterol determination by gas- and liquid-chromatography-Urgent need for harmonisation of analytical methods, J. Steroid Biochem. Mol. Biol., 2019, 190, 115-125.

34 D. Lütjohann, I. Björkhem, S. Friedrichs, A. Kerksiek, W. J. Geilenkeuser, A. Lövgren-Sandblom, D. Ansorena, I. Astiasarán, L. Baila-Rueda, B. Barriuso, L. Bretillon, R. W. Browne, C. Caccia, A. Cenarro, P. J. Crick, G. Fauler, G. García-Llatas, W. J. Griffiths, L. Iuliano, M. J. Lagarda, V. Leoni, A. M. Lottenberg, S. Matysik, J. McDonald, T. C. Rideout, G. Schmitz, V. S. Nunes, Y. Wang, C. Zerbinati, U. Diczfalusy and H. F. Schött, International descriptive and interventional survey for oxycholesteroldetermination by gas- and liquid-chromatographic methods, Biochimie, 2018, 153, 26-32. 
35 V. Leoni, T. Nury, A. Vejux, A. Zarrouk, C. Caccia, M. Debbabi, A. Fromont, R. Sghaier, T. Moreau and G. Lizard, Mitochondrial dysfunctions in 7-ketocholesteroltreated $158 \mathrm{~N}$ oligodendrocytes without or with $\alpha$-tocopherol: Impacts on the cellular profil of tricarboxylic cycle-associated organic acids, long chain saturated and unsaturated fatty acids, oxysterols, cholesterol and cholesterol precursors, J. Steroid Biochem. Mol. Biol., 2017, 169, 96-110.

36 A. Civra, V. Cagno, M. Donalisio, F. Biasi, G. Leonarduzzi, G. Poli and D. Lembo, Inhibition of pathogenic non-enveloped viruses by 25-hydroxycholesterol and 27-hydroxycholesterol., Sci. Rep., 2014, 4, 7487.

37 V. Piironen, J. Toivo and A. M. Lampi, New data for cholesterol contents in meat, fish, milk, eggs and their products consumed in Finland, J. Food Compos. Anal., 2002, 15, 705713.

38 C. Y. Tai, Y. C. Chen and B. H. Chen, Analysis, formation and inhibition of cholesterol oxidation products in food: An overview (Part II), J. Food Drug Anal., 2000, 8, 1-5.

39 A. Obara, M. Obiedziński and T. Kołczak, The effect of water activity on cholesterol oxidation in spray- and freezedried egg powders, Food Chem., 2006, 95, 173-179.
40 S. G. Anema, Effect of milk solids concentration on whey protein denaturation, particle size changes and solubilization of casein in high-pressure-treated skim milk, Int. Dairy J., 2007, 18, 228-235.

41 A. J. Angulo, J. M. Romera, M. Ramirez and A. Gil, Determination of cholesterol oxides in dairy products. Effect of storage conditions, J. Agric. Food Chem., 1997, 45, 4318-4323.

42 J. Nourooz-Zadeh and L. Appelqvist, Cholesterol oxides in Swedish foods and food ingredients: Butter and cheese, J. Am. Oil Chem. Soc., 1988, 65, 1635-1641.

43 V. Leoni, C. Mariotti, L. Nanetti, E. Salvatore, F. Squitieri, A. R. Bentivoglio, M. Bandettini di Poggio, S. Piacentini, D. Monza, M. Valenza, E. Cattaneo and S. Di Donato, Whole body cholesterol metabolism is impaired in Huntington's disease, Neurosci. Lett., 2011, 494(3), 245249.

44 J. Nourooz-Zadeh and L. Appelqvist, Cholesterol oxides in Swedish foods and food ingredients: milk powder products, J. Food Sci., 1988, 53(1), 74-79.

45 A. Anderson, A. Campo, E. Fulton, A. Corwin, W. G. Jerome 3rd and M. S. O'Connor, 7-Ketocholesterol in disease and aging, Redox Biol., 2020, 29, 101380. 